\title{
Process Control Improvement in Deep Drawing of Hemispherical Cups Made of GLARE Material
}

\author{
Hamza Blala ${ }^{1, *}$, Lihui Lang ${ }^{1}$, Lei $\mathrm{Li}^{1}$, Shahrukh Khan ${ }^{1}$ and Sergei Alexandrov ${ }^{1}$ \\ ${ }^{1}$ School of Mechanical Engineering and Automation, Beihang University, Beijing, China.
}

\begin{abstract}
Controlling the material flow under the blank holder in hydroforming is a delicate point that can be controlled by the blank holder force (BHF), cavity pressure (CP) and the blank holder gap (BHG). BHG is one of the effective parameters to control the material flow. A numerical and experimental approach studied the impact of the BHG on the Hydromechanical Deep Drawing (HDD) of a hemispherical cup made with 2/1 Glare sheets, including another two factors, CP and BHF. BHGs with different thickness was used in the experiments to form Glare Laminate. Simulation and experiment illustrate that an optimized value of these parameters has a good effect on the forming quality and depth of the final product. Finally, an appropriate value of the BHG is projected and the explanations of the failure modes are discussed.
\end{abstract}

\section{Introduction}

The Laminates are stacked plies of materials, the individual plies can be made of various materials, the utilization of laminates permits improvement and tuning of the material characteristic. [1-2]. Glare material belongs to the family of FMLs containing thin layers of metal sheet and unidirectional fiber layers implanted in an epoxy resin matrix [3-4]. The hydroforming of FMLs parts still face many difficulties for small and complicated parts due to two main reason, first one is related to the material, with forming of FMLs the cured prepreg layers are deformed elastically, and the metal layers are deformed plastically. The obtainable deformation by forming is often related to the amount of strain that the glass fibers can handle. The second reason is the importance of understanding the hydroforming process parameters such as the BHG, BHF, and CP. However, cost reduction during the manufacture of this kind of material became a prime issue. Gavas and Izciler investigate the effect of the BHG on the deep drawing of square cups using a gap ranging from $1 \mathrm{~mm}$ to $1.8 \mathrm{~mm}$ for $1 \mathrm{~mm}$ aluminum sheets with experimental approach their experimental implementation shows that the increase of the BHG permits more material to flow inside the die cavity without failure of the drawn part. Also, the results showed that it is impractical to use too large BHG because of the formation of wrinkling and buckling at the wall sides which cause tearing, and a reasonable optimized BHG has a great effect on the drawing quality of the final product [5]. Kusumi et al. In their study, suggested a utilization of gap supports during forming without blank holder for aluminized steel sheets using hot stamping, blank thicknesses of 1.0, 1.2 and $1.6 \mathrm{~mm}$ at 130 to $170 \mathrm{~mm}$ of diameters, the formability was improved and the maximum limiting drawing ratio reached was 1.71 for sheet thickness of 1.6 $\mathrm{mm}$, through a clearance of the flange at $2.8 \mathrm{~mm}$, the wrinkle happened at the flange area when the clearance of the flange was bigger. In comparison with ordinary blank holding, the formability was improved [6].

Moreover, Lang et al. in their research introduce a special procedure using assisted radial pressure in HDD with Al6016-T4 reveals that because of the clamping force the BHG may be less than the initial thickness during the drawing of the blank, [7]. 2017, Sherkatghanad et al. in their research present a new method using a semi-cured Glare blank as an alternative of a solidified blank in mechanical hydroforming of hemispherical parts, results shown an increase in the forming depth due to middle layer chance to move more freely between the $\mathrm{Al}$ sheets, but wrinkling and delamination has appeared and the depth target cannot be accomplished [8]. From the numerical simulations of Harith, no wrinkling can be observed when using BHG with a small value. The BHG has an influence on the distribution of equivalent plastic stresses and strains. For small BHG, uniform distributions of stresses and strains can be observed, this led to no wrinkle's appearance in the flange area. When increasing the gap value, this facility the material to flow rapidly at the initial stage of drawing [9]. Srirat et al. proposed another methodology using variable BHG trajectory and segmented blank holder shape. The optimization result showed an improvement in product quality [10].

Also, Wifi and Mosallam present non-conventional blank-holding techniques, to form a blank of Al 5182 with a thickness of $1 \mathrm{~mm}$, the result shows for a gap smaller than $0.2 \mathrm{~mm}$ the elastic $\mathrm{BH}$ was successful in wrinkling elimination [11]. BHF controls metal flow; it also affects thickness variation, strain path, stress path, and wrinkling behavior. Also, the forming limits depend 
on various process parameters such as friction between blank and blank holder, and friction effects on wall thickness distribution and surface quality [12]. In addition, Rizwan and Lang performed simultaneous forming by the HDD of the three-layer metallic blanks, their study revealed that using of cavity pressure in a controlled manner can improve the forming depth. Also thinning and wrinkling of multilayer parts are related to the BHF and CP in HDD [13]. From the literature review, all previous studies concerning the BHG investigation were done for monolithic material, in this paper, different thickness of BHG was used along with deferent levels of BHF and CP to form 2/1 Glare material using the HDD to analyze the influence of the BHG on the formability quality and depth.

\section{Materials and methods}

The 2/1 Glare laminate was selected, made with a 2024T3 Aluminum sheet with a thickness of $0.5 \mathrm{~mm}$ and $\mathrm{W}$ 9011 prepreg woven glass fiber with a thickness of 0.2 $\mathrm{mm}$, are cute to circular form with a diameter of $140 \mathrm{~mm}$, (Figure 1). Surface treatment for the aluminum blank was done using the phosphoric acid anodizing to improve the bonding characteristics of the $\mathrm{Al}$ layer and glass fiber, next the laminate is set in a vacuum to cure and to eliminate bubbles producing between the interlayer

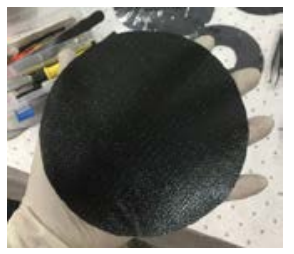

(a)

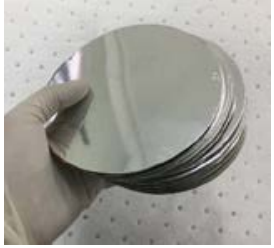

(b)
Fig. 1. (a) W-9011 prepreg woven glass fiber, (b) Aluminum 2024-T3.

Figure 2, demonstrate the compression phenomena after applying the BHF and the $\mathrm{CP}$ on the laminate system due to the clamping force, the presence of the resin, play a role of rubber or spring which decrease the thickness of the laminate, the value of this reduction is very small, but play a critical role along with the BHF and $\mathrm{CP}$, and help us to find the perfect combination of these parameters.

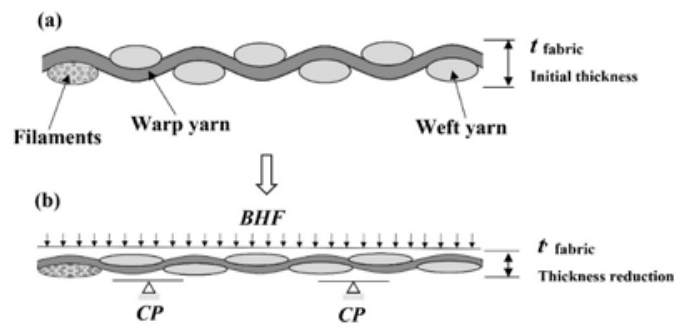

Fig. 2. Clamping force effect on the laminate thickness reduction, (a) cross-section of woven fabric, (b) cross-section of woven fabric under loading condition.

In the experiments, a 50-ton load capacity hydroforming machine was used for the forming test of
2/1 Glare laminate, the punch located on the upper part of the press and the die on the lower part. To apply the CP a hydraulic feed controller using two pumps located next to the machine and four hydraulic cylinders monitoring the blank holder. The Hydroforming press is linked to the software installed measuring and recording the drawing process factors. Tensile properties of the semi-cured fiber-reinforced metal laminates were tested on the CTM-100G universal testing machine. Table 1 illustrate the tensile test results gotten from this machine.

Table 1. Mechanical properties of Al 2024-T3 and the Glare laminate.

\begin{tabular}{|c|c|c|}
\hline Blank Type & Al 2024-T3 & 2/1 Glare \\
\hline $\begin{array}{c}\text { Number of } \\
\text { Al Layers }\end{array}$ & 1 & 2 \\
\hline Thickness (mm) & 0.5 & $0.5+0.2+0.5$ \\
\hline $\begin{array}{c}\text { Ultimate Tensile } \\
\text { Strength (MPa) }\end{array}$ & 193.25 & 195.11 \\
\hline $\begin{array}{c}\text { Yield Strength } \\
\text { at 0.2\% (MPa) }\end{array}$ & 109.63 & 110.30 \\
\hline $\begin{array}{c}\text { Modulus of } \\
\text { Elasticity (GPa) }\end{array}$ & 61.14 & 62.45 \\
\hline $\begin{array}{c}\text { r - Normal } \\
\text { Anisotropy Ratio }\end{array}$ & 0.880 & 0.897 \\
\hline
\end{tabular}

Drawing tests were done with different BHGs thickness to explore the impact of the gap on the forming quality. The dimensions of the mold are shown in Table 2. The selected BHG is given by spacer rings with a different thickness, between blank holder, and the die.

Table 2. Parameters of the equipment's.

\begin{tabular}{|c|c|}
\hline Parameters & Values [mm] \\
\hline Punch Diameter & 75 \\
\hline Die Diameter & 84 \\
\hline Die Radius & 12 \\
\hline Blank Holder Radius & 8 \\
\hline Blank Holder Diameter & 80 \\
\hline
\end{tabular}

BHG was chosen to start from $1 \mathrm{~mm}$ of thickness smaller than the Glare laminate thickness, and then increased the thickness of the BHG at an interval of 0.1 $\mathrm{mm}$ for each test. The punch load capacity was $16 \mathrm{KN}$, with a punch forming speed of $20 \mathrm{~mm} / \mathrm{min}$ for all the experiment was employed, tests are repeated until the fracture of the cup to define the maximum depth can be reached. At the end of the forming process, wrinkling and wall thickness distribution of the formed cup were examined.

To use the Taguchi designs method the factors of $\mathrm{BHG}, \mathrm{BHF}$, and $\mathrm{CP}$ are identified as the main variables, 
that may affect the forming behavior of the composite laminate, Table 3.

Table 3. Parameters of the equipment's.

\begin{tabular}{|c|c|c|c|}
\hline Specimens & $\begin{array}{c}\text { Blank } \\
\text { Holder } \\
\text { Gap [mm] }\end{array}$ & $\begin{array}{c}\text { Blank- } \\
\text { Holder } \\
\text { Force [KN] }\end{array}$ & $\begin{array}{c}\text { Cavity } \\
\text { Pressure } \\
\text { [Mpa] }\end{array}$ \\
\hline S1 & 1 & 4 & 3 \\
\hline S2 & 1 & 6.5 & 5 \\
\hline S3 & 1 & 8 & 10 \\
\hline S4 & 1 & 10.5 & 15 \\
\hline S5 & 1.1 & 4 & 5 \\
\hline S6 & 1.1 & 6.5 & 3 \\
\hline S7 & 1.1 & 8 & 15 \\
\hline S8 & 1.1 & 10.5 & 10 \\
\hline S9 & 1.2 & 4 & 10 \\
\hline S10 & 1.2 & 6.5 & 15 \\
\hline S11 & 1.2 & 8 & 3 \\
\hline S12 & 1.2 & 10.5 & 5 \\
\hline S13 & 1.3 & 4 & 15 \\
\hline S14 & 1.3 & 6.5 & 10 \\
\hline S15 & 1.3 & 8 & 5 \\
\hline S16 & 1.3 & 10.5 & 3 \\
\hline
\end{tabular}

\subsection{Finite element analysis}

ABAQUS finite element (FE) analysis models were used to simulate the drawing process. The simulation design for the Glare Laminate is shown in Figure 3, the model comprises of a punch, a blank holder, a die and two layers of $\mathrm{Al}$ laminates and one woven glass fiber in the middle. the punch and the blank holder move in the Yaxis direction. The aluminum elastic and plastic properties data are imported into the simulation, also the woven glass fiber elastic properties with the engineering constants are imported into the simulation. To reduce the computation time the die and the punch and blank holder are considered as rigid parts. The coefficients of friction between the aluminum layers and the woven fiber prepreg layer are $\mu=0.3$. Surface to surface contact is used, three tangential behaviors were introduced for modeling the contacts between surfaces, between the punch and the upper sheet $\mu=0.15 \mathrm{~mm}$, and $\mu=0.1$ used for the upper sheet and the blank holder, and $\mu=$ 0.05 used for the lower sheet and the die surface.

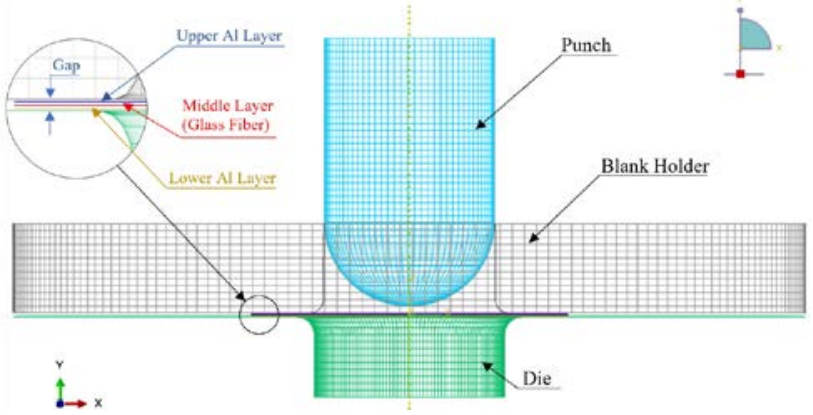

Fig. 3. Simulation layout for three layers of the laminate.

\section{Results and discussion}

\subsection{Effect of the process parameters on the wrinkling severity}

Table 4 illustrates the experimental results of the 2/1Glare laminate cup formed by the HDD process. Figure 4 shows cups formed at 1.2 and $1.3 \mathrm{~mm}$ of BHG, all specimens in simulation and experiment are shown the presence of wrinkling, demonstrating that a BHG equal or bigger than the laminate thickness wrinkling is the primary failure mode. At the BHG of $1 \mathrm{~mm}$, all formed cups showed very small or non-presence of wrinkling, but all Simple are failed due to tearing or fracture, signifying that a small BHG has a good impact on decreasing the severity of wrinkling but in another hand the possibility of failure due to tearing and fracture become much higher Figure 5. Results showed that the height of wrinkles that developed in the flange area reached $0.38 \mathrm{~mm}$.

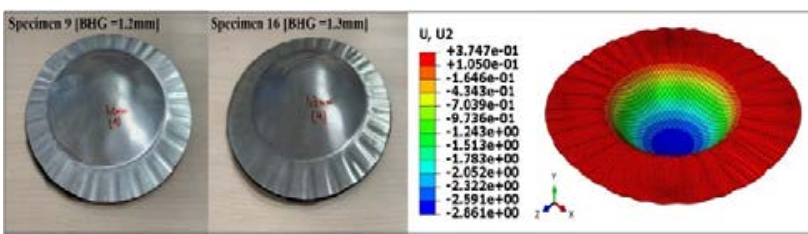

Fig. 4. Simulation and experimental results.

\subsection{Effect on stress distribution and forming quality}

Tensile stress is induced on the laminate in various areas in the die chamber. The sheet unbends along the cup wall. The flange suffers compressive hoop stress, compressive stress, and radial tensile stress due to the blank holding force. Figure 5 shows a formed cup at $1 \mathrm{~mm}$ of the BHG and variant levels of BHF and CP, as mentioned before, all formed cups showed non-presence of wrinkling, but all the samples failed due to tearing or fracture, signifying that this gap increases the possibility of failure, the maximum stress located in the fiber central region and the drawing stress of the fiber layer is in higher value, for the aluminum layers the maximum stress is located in the flange area, sidewall which undergoes the maximum deformation, the failure occurs due to the hard flow of the laminate from the flange to the die. The drawing stresses increase when reducing the BHG, because of the big friction between the FML layers and the shear stresses acted by the fluid during the drawing. 
Table 4. Results and analysis of the orthogonal experiment.

\begin{tabular}{|c|c|c|c|c|c|c|c|c|}
\hline & \multicolumn{3}{|c|}{ Factors } & \multicolumn{5}{|c|}{ Evaluation Index } \\
\hline & \multirow{2}{*}{$\begin{array}{l}\text { BHG } \\
{[\mathrm{mm}]}\end{array}$} & \multirow[t]{2}{*}{$\begin{array}{l}\text { BHF } \\
\text { [KN] }\end{array}$} & \multirow[t]{2}{*}{$\begin{array}{c}\text { CP } \\
\text { [Mpa] }\end{array}$} & \multicolumn{2}{|c|}{$\begin{array}{c}\text { Thinning } \\
\text { Rate \% (max) }\end{array}$} & \multirow{2}{*}{$\begin{array}{c}\text { Fiber } \\
\text { Glass Thinning } \\
\text { Rate \% } \\
\text { (Simulation) }\end{array}$} & \multirow{2}{*}{$\begin{array}{c}\text { Height of } \\
\text { Wrinkles } \\
\text { [mm] }\end{array}$} & \multirow{2}{*}{$\begin{array}{c}\text { Depth } \\
\text { Achieved } \\
\text { [mm] }\end{array}$} \\
\hline & & & & Upper & lower & & & \\
\hline S1 & 1 & 4 & 3 & 20.42 & 21.02 & 10 & 0 & 21 \\
\hline S2 & 1 & 6.5 & 5 & 20.56 & 21.28 & 10 & 0 & 22 \\
\hline S3 & 1 & 8 & 10 & 20.72 & 21.40 & 14 & 0 & 22 \\
\hline S4 & 1 & 10.5 & 15 & 20.78 & 21.80 & 14 & 0 & 20 \\
\hline S5 & 1.1 & 4 & 5 & 16.54 & 16.40 & 4 & 0 & 25 \\
\hline S6 & 1.1 & 6.5 & 3 & 16.64 & 16.58 & 4 & 0 & 25 \\
\hline S7 & 1.1 & 8 & 15 & 16.72 & 16.74 & 5 & 0 & 26 \\
\hline S8 & 1.1 & 10.5 & 10 & 16.78 & 16.86 & 5 & 0 & 26 \\
\hline S9 & 1.2 & 4 & 10 & 13.18 & 13.12 & 4 & 0.35 & 22 \\
\hline S10 & 1.2 & 6.5 & 15 & 13.26 & 13.26 & 4 & 0.29 & 22 \\
\hline S11 & 1.2 & 8 & 3 & 13.24 & 13.20 & 4 & 0.25 & 23 \\
\hline S12 & 1.2 & 10.3 & 5 & 13.28 & 13.28 & 4 & 0.20 & 23 \\
\hline S13 & 1.3 & 4 & 15 & 11.56 & 11.72 & 4 & 0.38 & 24 \\
\hline S14 & 1.3 & 6.5 & 10 & 13.20 & 13.02 & 4 & 0.35 & 24 \\
\hline S15 & 1.3 & 8 & 5 & 13.14 & 13.10 & 4 & 0.30 & 25 \\
\hline S16 & 1.3 & 10.5 & 3 & 13.24 & 13.20 & 4 & 0.30 & 25 \\
\hline
\end{tabular}

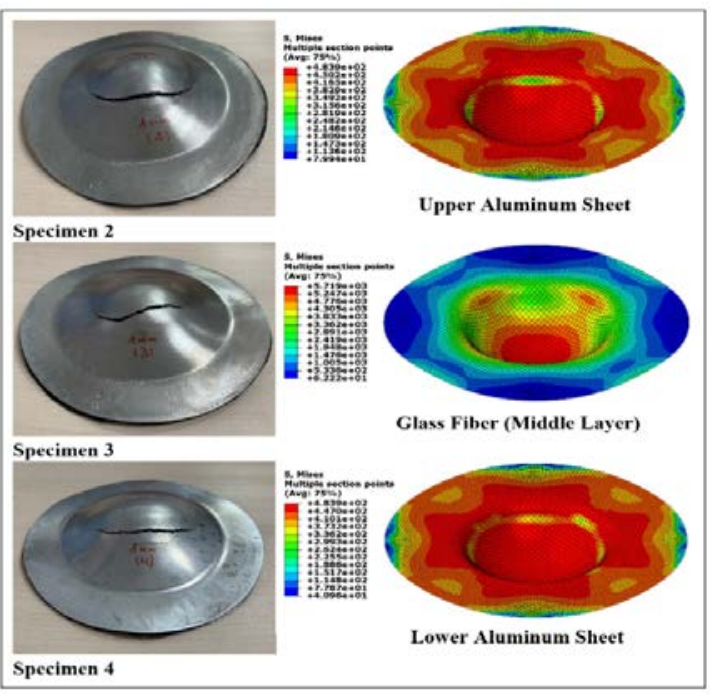

Fig. 5. Stress distribution of the laminates, a. $\mathrm{BHG}=1 \mathrm{~mm}$.

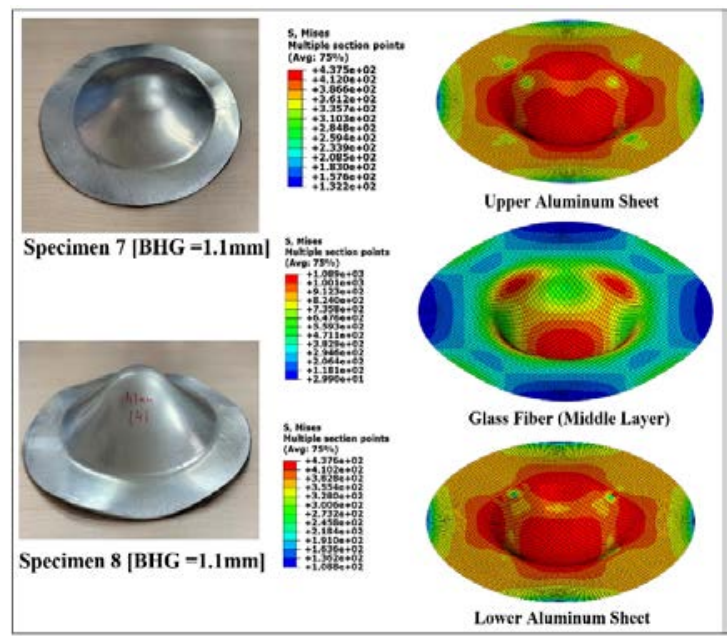

Fig. 6. Stress distribution of the laminates, a. $\mathrm{BHG}=1.1 \mathrm{~mm}$.
Figure 6 shows the simulation and experimental parts formed using the optimal simulation value S7, S8. The result indicates that the cup is very well-formed and the surface quality is good, with a significant depth of $26 \mathrm{~mm}$, due to the applied BHG of $1.1 \mathrm{~mm}$, and the BHF = (8 to $10.5 \mathrm{kN})$ and $\mathrm{CP}=(10$ to $15 \mathrm{MPa})$. This gap plays a significant role in the reduction of friction between the aluminum layers and the fiberglass but also guarantee the effectiveness of the continuous contact between the three layers to avoids wrinkling which in the same time has been guaranteed by the optimal value of the other possess parameters investigated in this paper.

\subsection{Effect on the thickness distributions}

The formed laminates parts cut at the center along diameter direction and the thickness of the Al upper and lower layers measured at different points on the cup. The predicted thinning using simulation analysis was closely related to the experimental values. From the experiments, the maximum thinning rate is observed to be $21.80 \%$, cups formed under BHG of $1 \mathrm{~mm}$. Figure 7 shows the wall thickness distribution of the formed laminate hemispherical cups. The highest thinning areas located in the punch radius area. From the curves, it can be realized that the lower $\mathrm{Al}$ blank, suffers the maximum thinning. In addition, it is important to note that BHG has a significant influence on the thinning of the part as especially the thinning of its external Al layers. To judge the wall thickness distribution curves, it's important to consider two aspects, first is the thinning value second, the similarity of the three curves, like in the case of the specimens (S9, S10) the no similarity of the curves indicates that the part has been wrinkled or torn, which is what has already happened in the experiments. Using a BHG of $1 \mathrm{~mm}$, the thinning rate reached $21.80 \%$ for aluminum layers and $14 \%$ for the glass fiber which is a very high value of thinning, this due to the glass fiber 
layer low elastic modulus, and the big friction between the layers produced by this small gap, this explains the failure of all the experiments held in this gap value. According to the simulation and experiment results, the specimens (S7, S8) the curves shown a good similarity and thinning range values are reasonable $16 \%$ for aluminum and $5 \%$ for the prepreg glass fiber. The formed cups in this BHG are very well-formed and the surface quality is also quite good and without delamination, with a signified depth reached $26 \mathrm{~mm}$. For BHG equal or bigger than the laminate thickness, the case of specimens (S9, S10) this parts drawn at BHG of 1.2 and $1.3 \mathrm{~mm}$ using a different BHF and $\mathrm{CP}$, the thinning rate was small compared with the previous samples, $13 \%$ for the aluminum layers and $4 \%$ for the glass fiber due to the easy flow of the material inside the die, in another hand, the presence of the wrinkling was very serious, this explains the non-uniformity of the shape of thickness distribution curves for the three-layer Glare laminate drawn in this condition.
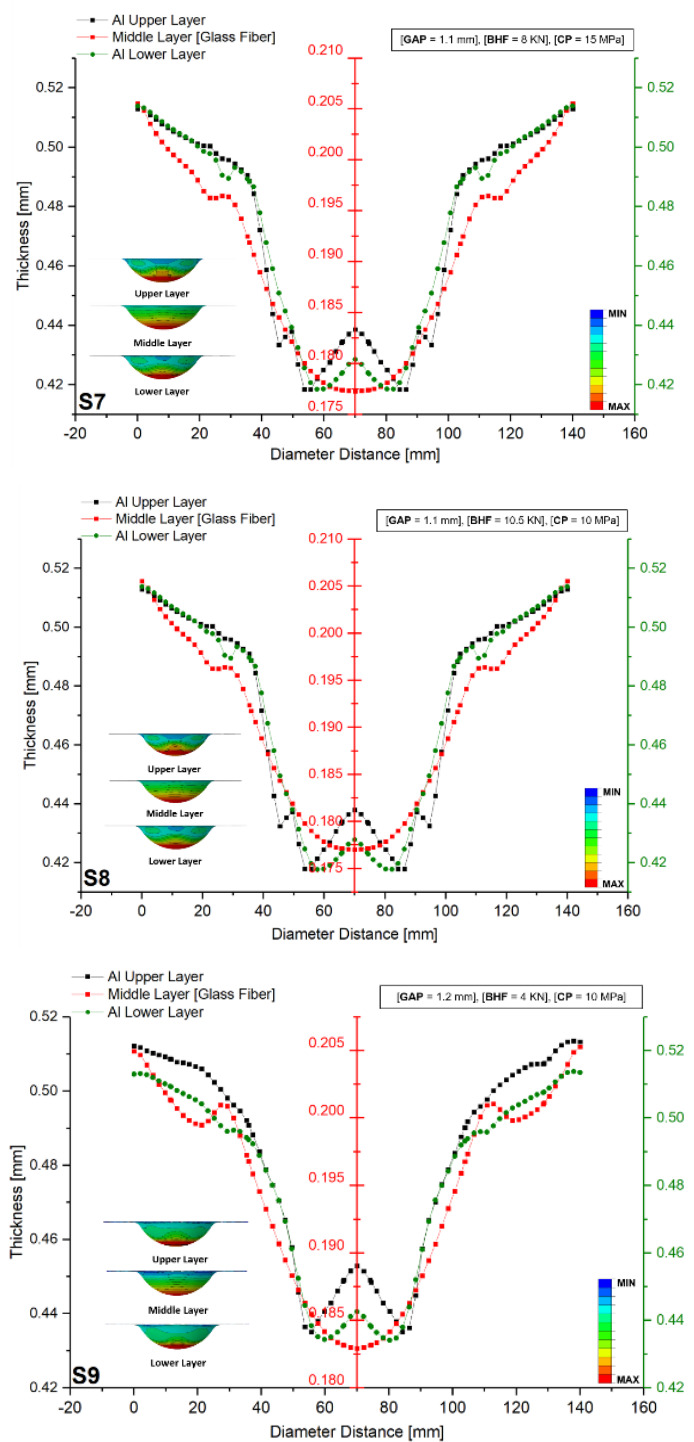

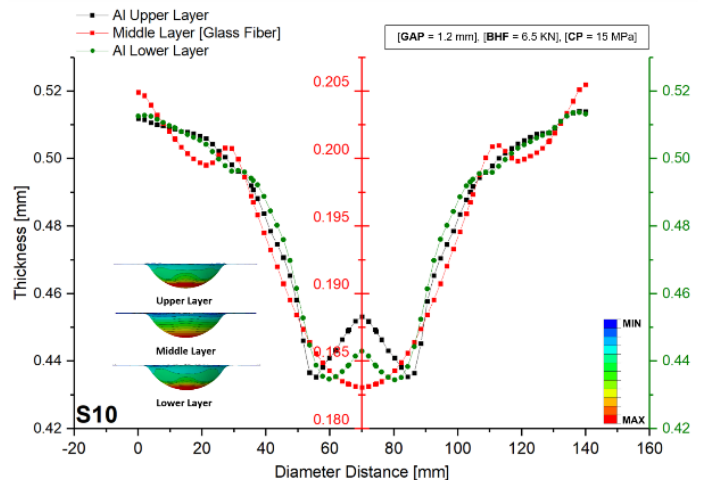

Fig. 7. Wall thickness distribution of three-layers.

\section{Summary}

This paper investigates the 2/1 Glare material forming behavior using the mechanical hydroforming process. A hemispherical cup has been formed, the effect of process parameters such as the BHG, $\mathrm{CP}$ and the BHF on the final part quality (i.e., wrinkling, fracture, depth achieved) has been investigated. Numerical simulations to estimate the optimal process parameters were carried out which showed good alignment with the experiment results. Wrinkling and thinning of laminate cups rely upon both BHF/CP, CP higher than the optimal promote the emergence of the wrinkling starting with the lower Al layer which in direct contact with fluid pressure, at $\mathrm{CP}$ less than the optimal values, wrinkling and fracture were seen. Based on the finite element simulation results for 2/1 Glare laminate HDD of the hemispherical cup, the optimal $\mathrm{BHF}$ and maximum $\mathrm{CP}$ were determined to be 8 to $10.5 \mathrm{kN}$ and 10 to $15 \mathrm{MPa}$, with a BHG of $1.1 \mathrm{~mm}$ which resulted in a good part with significant depth of $26 \mathrm{~mm}$. Meanwhile, these predicted process parameters obtained were tested in the hydroforming Machine to validate and improve the developed optimization approach. By taking into account the clamping force effect on the laminate thickness reduction, it makes it very clear that the effect of the BHG is very important in the elimination of the wrinkles, in addition to facilitating the flow of the laminate smoothly in the die without provoking tearing. By using These obtained predicted process parameters and take into consideration the BHG is believed to significantly improve the drawing process and product quality.

This research work is supported by the National Science Foundation of China (51675029) and the Science and Technology Project of Sichuan Province (2019YFSY0034).

\section{References}

1. Jong, T. W. De. Forming of laminates. ISBN 90407-2506-3, Delft University Press, (p- 2) (2004)

2. L.B. Vogelesang, A. Vlot. Development of fiber metal laminates for advanced aerospace structures. J. Mat. Proc. Tech. 103, 1-5. https://doi.org/ 10.1016/S0924-0136(00)00411-8. (2000) 
3. Vlot, Ad, and Jan Willem Gunnink. Fibre metal laminates: an introduction. Dordrecht: Kluwer Academic Publishers. (pp. 12-39). https://doi.org/10.1007/978-94-010-0995-9 (2001)

4. S. Y. Park, W. J. Choi, H. S. Choi. A comparative study on the properties of Glare laminates cured by autoclave and autoclave consolidation followed by oven post-curing. I. J. Adv. Manuf. Tech. 49, 5-8. https://doi.org/10.1299/jamdsm.6.42010.1007/s0017 0-009-2408-x (2010)

5. M. Gavss, M. Izciler. Effect of blank holder gap on deep drawing of square cups. Mat. and Desi. Reigate. 28, 1641-1646. https://doi.org/10.1299/jamdsm.6.420 10.1016/j.matdes.2006.03.024 (2007)

6. Kusumi, K., Nomura, N., Yamamoto, S., Nakata, M., Abe, M., \& Suehiro, M. Improvement of cylindrical deep drawability in hot stamping. Proc. Eng. 81,1719-1724.

https://doi.org/10.1299/jamdsm.6.42010.1016/j.proen g.2014.10.220 (2014)

7. L. Lang, J.Danckert, K. B. Nielsen, Investigation into hydrodynamic deep drawing assisted by radial pressure: Part I. Experimental observations of the forming process of aluminum alloy. J. Mat. Proc. Tech. 148, 119-131, https://doi.org/10.1299/jamdsm.6.42010.1016/j.jmatp rotec.2004.01.053 (2004)

8. E. Sherkatghanad, , L. Lang, , S. Liu, , Y. Wang. Innovative approach to mass production of fiber metal laminate sheets. Mat. and Manuf. Proc. 33, 552-563.

https://doi.org/10.1080/10426914.2017.1364864 (2018)

9. H. Yarub Maan. The Influence of blankholder gap on deep drawing process using finite element method, Int. J. of Mec. Eng. and Tech 9 (13), pp. 1510-1518. http://www.iaeme.com/IJMET/issues.asp?JType=IJ MET\&VType=9\&IType=13 (2018)

10. J. Srirat, K. Yamazaki, S. Kitayama. Optimization of segmented blank holder shape and Its variable blank holder gap in deep drawing process. The Jap. Soci of Mech. Eng. http://jairo.nii.ac.jp/0034/00031920, https://doi.org/10.1299/jamdsm.6.420 (2017)

11. A.S. Wifi, A. Mosallam, A.B. Act. Some aspects of blank-holder force schemes in deep drawing process. J. of Achiev. in Mat. and Manuf. Eng (2007)

12. C. Pal Singh, G. Agnihotri. Study of deep drawing process parameters: A Review. Int. J of Sci. and Res. Pub (IJSRP), 5, Issue 2, February (2015)

13. R. Zafar, L. Lihui, Z. Rongjing, \& W. Shaohua. Formability analysis of fiber metal laminates using rubber sheet and forming techniques. 44-47. (IBCAST). https://doi.org/10.1299/jamdsm.6.420 10.1109/IBCAST.2014.6778118 (2014) 